\title{
Nursing students' experiences on blogging in the classroom: Linking between ethics and pedagogy
}

\author{
I ris Epstein ${ }^{1}$, Ashleigh Ray ${ }^{2}$ \\ 1. Centre For Health Science, George Brown College, Toronto, Canada. 2. York University, Toronto, Canada. \\ Correspondence: Iris Epstein. Address: Centre For Health Science, George Brown College, Toronto, Canada. Email: \\ iepstein@georgebrown.ca
}

Received: July 19, 2013

Accepted: November 3, $2013 \quad$ Online Published: January 7, 2014

DOI : 10.5430/jnep.v4n4p37

URL: http://dx.doi.org/10.5430/jnep.v4n4p37

\begin{abstract}
This paper reports students' perspectives on using blogging in an undergraduate nursing classroom. Blogging refers to a series of entries with limited word count. Several anecdotal reports focus on the potential advantages (e.g., increasing students' writing, reflecting, collaborating, participation and critical thinking skills) of blogging in education. Yet limited reports discuss its challenges. We argue that in order to better understand the use of blogging in the classroom we need to look more closely at students' values, beliefs and expectations. Thus, to better understand teaching and learning and evaluate blogging we used Gesler's theory of therapeutic landscape. Students' retrospective accounts revealed two overarching themes: students' experiences and students' responses to blogging. Despite the fact that students experienced and valued blogging in their everyday lives, their responses to in-class blogging were not always positive.
\end{abstract}

\section{Key words}

Nursing students, Blogging, Ethics, Pedagogy

\section{Introduction}

The term "blog" is derived from the words web and $\log ^{[2]}$. A blog refers to a series of entries with limited word count (e.g., between 50 and 500 characters) posted to a specific webpage in learning environments (e.g., Blackboard, Moodle, WebCT) or public environments (e.g., Twitter) ${ }^{[2]}$ which can be viewed by multiple readers ${ }^{[3,4]}$. In the last decade blogging has become popular in the context of education as it is believed to be simple to use, easily accessible and inexpensive ${ }^{[3,5]}$. Furthermore, it allows teachers and learners to interact, share ideas and resources, and increases student participation ${ }^{[5]}$. Despite its popularity there are limited reports regarding blogging as an education tool.

In this paper, we discuss a study in which blogging was used as a teaching tool and evaluated by Gesler's ${ }^{[1]}$ therapeutic landscape concept. Blogging was embedded in the Blackboard online learning system as part of a first year undergraduate nursing course offered in 2013. The teacher, with the assistance of two master's students, used blogging as a method for increasing students' $(\mathrm{n}=72)$ participation in class discussions about course topics. This particular nursing theory course focused on the social, economic and political influences in nursing and required students' active participation to better apply abstract concepts to nursing. Posting an open ended question during lectures as a blog was used successfully by several authors ${ }^{[6-8]}$. However, for us, this activity posed several challenges. Thus, the purpose of this paper is to report 
nursing students' experiences of blogging in the classroom which will help educators to make a connection between nursing blogging and pedagogy to assess the advantages and disadvantages of blogging as a teaching tool.

\section{Literature review}

Yau and Cheng ${ }^{[9]}$ reported that in the last decade both younger and older students in higher education have been using technology in their everyday lives and many hoped that their education would embrace technology more. Blogging is an example of a technology that has been increasingly used in education both by teachers and students ${ }^{[4]}$. Educators have woven blogging into their curriculum as they believed it would enhance students' skills in reading, writing, and collaboration ${ }^{[10-12]}$. Several authors used blogging in education to communicate with students ${ }^{[2,10]}$ and as a discussion/ debate/collaboration board where the teacher or students posted questions related to course content ${ }^{[13]}$. Blogs have also been used as a resource centre where the teacher and students collected resources on topics throughout the course ${ }^{[13]}$. Huang and $\mathrm{Lo}^{[2]}$ suggested blogs are an effective method of building a sense of community for students to share ideas in a safe environment.

The use of technology in education has dramatically increased in the last decade. Mishra and Koeher ${ }^{[14]}$ called on educators to be constantly aware of the links between technology and pedagogy. Some nursing authors used technology (e.g. simulation) mainly to increase the outcomes of students' clinical technical skills ${ }^{[15,16]}$. There are also anecdotal reports on the use of iPods and other MP3 devices as they are becoming a way for nursing students to learn how to care for patients, perform procedures and prepare for tests ${ }^{[17]}$. Other disciplines, such as medicine and dentistry, have experienced the successful application of blogging in education ${ }^{[5,11,13,18-20]}$.

Despite the increased use of blogging in nursing education there are limited reports on its link to pedagogy ${ }^{[10,21]}$. We argue that educators need to start focusing on how and why they are using blogging. Ironside ${ }^{[22]}$ suggested that for students to embrace innovation teachers need to have discussions with them regarding the use of new pedagogies in nursing education. If both teachers and students understand the pedagogy behind the use of a technology (e.g., blogging) in nursing education, the technology can not only increase students' abilities to learn technical skills but also enhance their thinking skills ${ }^{[14]}$.

Critical thinking (CT) has long been a valued curriculum outcome requirement for nursing ${ }^{\text {[23] }}$. The definition of critical thinking includes cognitive skills (the ability to predict and transform knowledge) and affective skills (intuition, open mindedness and creativity) ${ }^{[24]}$. Several studies implicitly linked the use of technology and students' abilities to be creative and reflective and to make connections between theory and practice ${ }^{[5,11-13,18-20]}$. For example, Maag ${ }^{[13]}$ suggested that, when used correctly, blogging gives students time to reflect prior to responding to questions. Creating opportunities for students to participate in class discussion through blogging has also been linked to supporting students' critical thinking ${ }^{[25,26]}$.

The ability to think critically requires transferring theoretical knowledge to the clinical environment. For example, if students are being taught how to be advocates for their clients, blogging can serve as a platform to share and discuss case studies and invite students to apply advocacy concepts taught in class. Roland and colleagues ${ }^{[5]}$ and Brown ${ }^{[18]}$ reported that blogging allowed students to reflect on their clinical practice using abstract concepts. In addition, blogging was reported to increase students' opinions on concepts discussed in class. Mortensen and Walker (as cited in Placing, Ward, Peat \& Teixeira) ${ }^{[27, \text { p.161] }}$ discussed how the blogger requires "a confident and clear voice of one's own and the ability to formulate and stand by opinions". Similarly, Galer-Unti ${ }^{[28]}$ discussed the use of blogging to allow students to express their voice.

The ability to be a critical thinker is also linked to students' skills in collaborating, engaging, and being open to other perspectives and disciplines ${ }^{[29]}$. Interactions with others during blogging broaden knowledge by allowing students to construct and synthesize complex course concepts ${ }^{[3]}$. Grassley and Bartoletti ${ }^{[10]}$ discussed blogging as a tool for educators 
to promote student-peer support and collaborative dialogue. Chu and colleagues ${ }^{[3]}$ and Maag ${ }^{[13]}$ used blogging as a way to promote student reflection after clinical practice. Chu and colleagues ${ }^{[3]}$ explained that blogging can essentially serve as a journal which encourages students to write on their and others' experiences. Several authors reported the advantage of blogging in co-creating knowledge ${ }^{[3,4]}$ and believed that it augmented students' interests and engagement in the course content.

Despite these anecdotal reported successes, these authors did not researched blogging and how it can influence students' critical thinking. Authors were glorifying blogging and some were calling educators to" use blogging correctly" in the classroom ${ }^{[13, \text { p.21] }}$ and better express students' “ voices” ${ }^{[28, ~ p .161]}$. However, there are no clear directions on how to use blogging correctly. When we used blogging in our classroom not all students participated and we encountered many challenges that the literature on blogging had not discussed. Thus, when we wanted to explore how we could better link the use of blogging to nursing pedagogy our first step was to explore students' perspectives. We argued that to understand blogging as a teaching tool we needed to explore not only its technical contributions but also the educational blogging environment.

Gesler's ${ }^{[1]}$ concept of therapeutic landscape' (TL) will guide our evaluation of the blogging environment. According to Gesler an environment is composed of social (relationships between and among people) and physical landscape (e.g., what you see, touch, smell and taste in your environment). According to Gesler, ${ }^{[30, p .70]}$ "one can gain an understanding of culture by reading and interpreting the landscape created as one would read a text”. Thus, what considered a landscape of learning for one might not be for another (as individual create meaning of landscapes and landscape affect individuals' meaning in significant ways). Gesler suggested that social and physical environments are set to be a result of particular hierarchy of power. In this paper, we used blogging in a classroom environment as it assumed to be a type of therapeutic landscape built by the teacher. The teacher in the classroom has the power in terms of when and how blogging should be used who and how students' should be rewarded. Thus, the blogging in the classroom environment includes a physical environment (e.g., class layout, light, screens, signs and symbols) and a social environment (e.g., relationships among students and between students and teacher; rules that need to be followed). We suggest that the social and physical environments affect, and are affected by, how blogging in the classroom is said to be used by the teacher and perceived by students. Since Gesler ${ }^{[1,30]}$ first introduced the concept of therapeutic landscape many researchers have applied it to understand the relationship between environments learning health and health promotion ${ }^{[31,32]}$.

\section{Method}

We used blogging in the first 4 weeks of the semester at the beginning of the class. As the teacher was discussing the weekly content (e.g., lectures, group work) a question was posted on a separate screen (See Appendix A) and students were asked to post their answers (in 150-200 characters) during the 3 hour class time. Several times during the class the teacher would refer to students' postings and link their ideas to the concepts discussed. All students had to participate in the blog at least once during these 4 weeks however, there was no penalty for those students who did not participate. For example, the class topic in Week 1 was nursing values. However, during the 3hr class only 17 students out of 72 in the class posted replies, and these were brief 2-4 word answers (e.g., "nurses values are honesty"; "being truthful”; "being accurate”). Thus, despite making blogging mandatory (at least once during the 4 weeks) from Weeks 1-4 the teacher received a total of only 66 postings and most came from the same few students. Therefore we wanted to further explore why our blog was not used by all students. At the end of the semester, Week 12, we distributed an anonymous online survey to the students to explore their perspectives, as undergraduate nursing students, on using blogging in the classroom. Gesler ${ }^{[1,30]}$ posited that societies develop public symbols to express rules and power dynamics of particular landscapes. These symbols are often ambiguous as they hold multiple meanings and thus can be interpret in different ways. Thus, in order to better understand students' perspectives on the blogging landscape symbols multiple data collections methods need to be included (e.g., using qualitative and quantitative data collections with participants.) The survey included nine quantitative questions which used a 3-point Likert scale (e.g., 1 - never; 2 - occasionally; 3 - often ) to describe frequency 
count of the data (e.g., how often student blog) and four open ended questions (See Appendix B for survey sample). Using only 3 Likert scale limits the quantitative analysis options ${ }^{[33]}$ as we could only use descriptive statistics.

\section{Analysis}

Data analysis was an iterative process between thinking and organizing the data, generating codes and using various analytical strategies. We used deductive analysis following Miles and Huberman ${ }^{[34, \mathrm{p} .58]}$, who explained that one method of creating codes entailed "creating a start list”. Thus, we first asked what were the advantages, disadvantages, and suggestions for changes students discussed regarding blogging in the classroom. After reading and re-reading this start list we developed "more inferential and explanatory" themes ${ }^{[34, \text { p.57] }}$. Miles and Huberman ${ }^{[34]}$ suggested several techniques to verify conclusions from data. For example, the traditional way to report on a Likert scale is to sum the values of each selected option (e.g., never, occasional often) and create a score for each question. We then used the score to represent a particular trait (e.g., most students scored "often" for blogging in their everyday life but scored "occasional” for blogging in class). Thus this adding and counting also allowed us to look for contradictions as a way to further characterize data. We used the literature and theory to help us better understands the data and the emerging themes. For example, we were guided by Gesler's ${ }^{[1]}$ concept of therapeutic landscape and read for "social and physical environments"; and we read for relationships and placing students within social structures of power to highlight how students described social forces as enabling or constraining.

\section{Findings}

Students' perspectives on blogging in the classroom were based on the sample postings collected over 4 weeks and the survey results. Out of the class $(\mathrm{n}-72)$ about $26 \%(\mathrm{n}=30)$ completed the survey. The majority were female $(\mathrm{n}-27)$ and between the ages of 17 and 21, two were aged between 22 and 28, one was in the 28-35 age group, while two did not indicate their age. Students' retrospective accounts revealed two overarching themes: A) student experiences: the value of blogging; B) students' responses to blogging in the classroom.

\section{Student experiences: Value blogging}

Students' retrospective accounts showed that they experienced and valued (16 out of 30 students) blogging in their everyday lives outside the classroom (17 out of 30 students rate "occasion" and used blogging at least once between Weeks 1-4 during the 3hr class). One participant said, "when I wake up I blog, after I eat breakfast I blog, my friends and I blog about everything, I mean everything," and another participant said, "I blog with people I trust; we share thoughts and opinions through the day not only in class." Another said, "Sure I blog outside classroom all the time; it is a good way to keep a conversation going among friends." Many of the students' retrospective accounts showed they valued the experience of blogging because it allowed them to share ideas in a safe place.

\section{Students' responses to blogging in the classroom}

Despite participants' overall familiarity with and use of blogging in their everyday lives, several students chose not to participate in the classroom blogging activities. One reason included blogging being a disruption to thinking and learning during class. For example, many students were used to listening to the teacher and taking notes, but when they $(n=9)$ had to blog at the same time they felt distracted. For example, one participant said, "This blogging is disruptive because it focuses my attention on [having to write my blog] rather than listening to the teacher. Another participant explained, "I did not know which screen to focus on," and blogging "affects my note taking. "Two other participants argued that "sometimes it’s slightly distracting having to listen to the prof and look at the blog at the same time."

Another reason students $(\mathrm{n}=11)$ responded negatively to blogging is a lack of clear instructions and expectations for the blogging assignments, a lack which resulted in the students' responding to the in-class blogging by not engaging. About 10 
out of 30 participants reported feeling powerless and sensed a disconnection between the blog requirements and their final grade. One student said, "I did not like this blogging but I could not say anything." Another student said "I wanted to tell the prof that if we have to blog then we should be marked for it, but I did not." Many students' suggestions for change focused on clarifying the blog expectations. For example, 7 out of 30 students suggested rendering the blogging a marked mandatory activity. In addition, 9 out of the 30 students viewed blogging as a way to ask questions and the teacher to answer. Giving students options was suggested by some students $(n=16)$. For example, one student said she would like it "if the teacher posts the question then gives several questions and the option to choose Students wanted options of questions to answer, of customizing their blog (e.g., with images or color) and the option to post anonymously. One participant commented, "I think blogging in the classroom would be effective if it was completely anonymous.

A final sub-theme included technical issues when using the blog. For example, 16 out of 30 checked off in the survey that blogging in class was never easy; some (4 out of 30) wanted a tutorial or instructions on how to use the blog in the classroom. Additionally, 10 out of 30 participants found they did not have sufficient time to blog and 22 out of 30 reported they would have used the blog if given more time. One participant stated, "Blogging should be available after class so we have time to think and write a meaningful post

\section{Discussion}

Although students experienced and valued blogging in their everyday lives their responses to in-class blogging were not always positive. In their everyday lives blogging allowed them to express and share ideas with their friends in a safe place. Yet, when we used blogging in the classroom many did not participate and found the blog distracting to their learning. They discussed how the blogging assignments required work with minimal reward (e.g., no marks assigned) and had no clear instructions despite our spending time during the first class explaining the assignment.

Using Gesler's ${ }^{[1]}$ therapeutic landscape can assist us to better understand our teaching and learning environments. According to Gesler ${ }^{[1]}$, the physical and social environments affect, and are affected by, human actions. The social environment includes those social relationships which are the result of particular hierarchical arrangements of power (individual or institutional) which are reflected in the attributes of individuals, such as age, gender, and culture, and create inequalities. Several instances in participants' accounts brought to the surface the existing power relationship between teacher and student. For example, in their everyday lives our students felt comfortable and safe to blog among friends, yet in the classroom it was not as safe, particularly in the first 4 weeks of the semester. Thus, when teachers decide to use blogging perhaps the blogging should be introduced after a few weeks, giving students' time to better introduce and connect with each other. We felt that students' feeling unsafe also played out when students asked to have "more anonymous posting opportunities" for fear of being judged by others. Some felt powerless and uncomfortable asking the teacher to add marks to the assignment. For some students the physical environment with the additional screen for blogging was viewed as "distracting to my learning; I just wanted to focus on the PowerPoint slide Also included in the physical environment is the teacher's posting. Several students wanted to see the teacher's posting answering the weekly question.

The goal of this research on blogging is its attempt to start a discussion on how ethical issues might emerge when we use blogging in education. Applying Gesler ${ }^{[1]}$ in this research allowed us to see the hierarchical arrangements of power that might create inequalities and influence how individuals interact with each other. These hierarchical arrangements of power can create ethical conflict that may be produced between individuals' personal and professional values, teacher and student and/or between the student and the broader educational system. According to Gesler ${ }^{[1]}$ such ethical conflicts may be difficult for the outsider to articulate, measure and see clearly, as symbols in our physical and social environments are often ambiguous, or are taken for granted so that they are no longer noticed. Students' accounts revealed that they wanted to be anonymous in their posting and when they were not some felt threatened. Similarly, Maag ${ }^{[13]}$ explained that, for students, being anonymous was considered a "safe space" and promoted collaboration. When postings are anonymous 
students may be more confident to speak up ${ }^{[35]}$. Another example of ethical encounter is that students wanted to be rewarded for their participation in the in-class blogging. Simply asking them to do work and post answers was not viewed as fair. In their suggestions for change several students requested to be marked.

Theories of caring and caring pedagogy may also help us address these power differences and link education and technology. Caring can be expressed in relationships in both formal and informal ways (e.g. caring for and caring about ${ }^{[36]}$ to better relate to others ${ }^{[37-39]}$. For example, on the one hand a teacher using blogging needs to include clear expectations and written instructions on grading (formal caring). Chu and colleagues ${ }^{[3]}$ found that when the blogging is graded, the volume of blogs by students tends to be higher and the blogs longer. As well, we need to give students opportunities to feel supported and rewarded, to have choices, and to have fun while participating in blogging (informal caring). Students' retrospective accounts suggested more "fun" physical and social environment opportunities that would allow them to post “colorful images” to describe their ideas. Our results finding was consistent with Huang and colleagues ${ }^{[2]}$ who confirmed that undergraduate students participated more in blogging when allowed to personalize and use images and symbols instead of words in their blogs. According to $\mathrm{Al} \mathrm{Fadda} \mathrm{and} \mathrm{Al}$ Yahay ${ }^{[40]}$, their students were allowed to blog and were given the freedom to create and add images to their blogs to personalize them. Other studies reported the use of graphs and images to help students better articulate their ideas ${ }^{[2,13]}$. Some students connected with other students after class for support and others networked beyond the classroom, an activity which Williams and Chinn ${ }^{[41]}$ suggested is an example of fun and creativity in focused learning. These examples of formal and informal caring will co-create social and physical environments for better teaching and learning.

Garno ${ }^{[38]}$ suggested one method of encouraging a caring presence is through connectedness, paying closer attention to differences between and among people. Garno ${ }^{[38]}$ suggested educators must surrender some control over the learning environment. This is consistent with our findings that students wanted more control over the blog, such as giving them more options and choices in terms of timing of blogs, their desire for anonymity, and wanting marks for blogging. Sharma ${ }^{[35]}$ encouraged teachers to give students options to be anonymous, particularly when the topic for the blog discussions was very sensitive. Inviting students to collaborate and co-create blogging in the classroom can reduce the power hierarchy of teacher and student and can encourage the blog to be a therapeutic landscape ${ }^{[1]}$.

\section{Conclusion}

Blogging has been used not only by students in their personal lives but has also permeated higher education. Several anecdotal reports have found blogging to be a valuable teaching tool to increase students' clinical and critical thinking skills. Ours was a course evaluation of a small sample size $(n=30)$ of students' retrospective accounts of blogging in the classroom. Further research is needed to explore the pedagogy of this particular technology and to link student demographics to their experiences with blogging. Further research is needed to compare undergraduate and graduate nursing students. Limitations include the small sample size, limited quantitative questions asked and the 3 point Likert scale used as we only did descriptive statistics. Our evaluation revealed that despite students' familiarity with and use of blogging in their personal lives many found blogging in the classroom created a difficult learning environment. Using Gesler's ${ }^{[1]}$ ideas of the therapeutic landscape helped us to understand the need to explore students' perspectives on these physical and social environments, as understanding their values and perspectives on blogging will better enhance learning and teaching experiences.

\section{References}

[1] Gesler WM. Therapeutic landscapes: medical issues in light of the new cultural geography. Social Science \& Medicine. 1992; 34(7): 735-746. http://dx.doi.org/10.1016/0277-9536(92)90360-3

[2] Huang YH, Lo YF. What makes blogging attractive to bloggers: a case of college-level constituency users. Journal of Computer Assisted Learning. 2012; 28: 208-221. http://dx.doi.org/10.1111/j.1365-2729.2012.00482.x 
[3] Chu S, Chan C, Tiwari A. Using blogs to support learning during internship. Journal of Computers \& Education. 2012; 58(3): 989-1000. http://dx.doi.org/10.1016/j.compedu.2011.08.027

[4] Halic O, Lee D, Paulus T, Spence M. To blog or not to blog: Student perceptions of blog effectiveness for learning in a college-level course. Journal of Internet \& Higher Education. 2010; 13(4): 206-213. http://dx.doi.org/10.1016/j.iheduc.2010.04.001

[5] Roland J, Johnson C, Sawin D. "Blogging” as an educational enhancement tool for improved student performance: A pilot study in undergraduate nursing education. New Review of Information Networking. 2011; 16(2): 151-166. http://dx.doi.org/10.1080/13614576.2011.619923

[6] Cheng G, Chau J. A comparative study of using blogs and wikis for collaborative knowledge construction. International Journal of Instructional Media. 2012; 38(1): 71-78.

[7] McGlinn MM, Lee JK. "You have to know the past to (blog) the present:” Using an Educational Blog to engage students in U.S. History. Computers in the Schools. 2012; 29(1-2): 118-134. http://dx.doi.org/10.1080/07380569.2012.656543

[8] Wetzel D. 5 Benefits for creating a classroom environment for student blogs. 2010. Available from: http://www.suite101.com/content/5-benefits-for-creating-a-classroom-environment-for-student-blogs-a285167\#ixzz15ZM3xHy9

[9] Yau K, Cheng ALF. Students age differences of confidence in using technology for learning in higher education, TOJET: The Turkish Online Journal of Educational Technology. 2012; 11(3): 308-311.

[10] Grassley J, Bartoletti R. Wikis and blogs: Tools for online interaction. Nurse Educator. 2009; 34(5): 209-213. PMid:19726963 http://dx.doi.org/10.1097/NNE.0b013e3181b2b59b

[11] Kang I, Bonk C, Kim M. A case study of blog-based learning in Korea: Technology becomes pedagogy. Internet and Higher Education. 2011; 14: 227-235. http://dx.doi.org/10.1016/j.iheduc.2011.05.002

[12] Moule P. Log on to learn. Nursing Standard. 2011; 25(32): 61. PMid:21563543

[13] Maag M. The potential use of "blogs” in nursing education. CIN: Computers, Informatics, Nursing. 2005; 23(1): 16-24.

[14] Mishra P, Koeher M. Technological pedagogical content knowledge: Framework for teacher knowledge. Teacher College Record. 2006; 108(6): 1017-1054. http://dx.doi.org/10.1111/j.1467-9620.2006.00684.x

[15] Medley CF, Horne C. Using simulation technology for undergraduate nursing education. Journal of Nursing Education. 2005; 44(1): 31-34. PMid:15673172

[16] Nehring WM. High-fidelity patient simulation in nursing education. 2010. Sudbury, MA: Jones and Bartlett.

[17] Wood D. Blog: Technology and devices. 2013. Available from:

http://www.nursezone.com/nursing-news-events/devices-and-technology/Student-Nurses-Embrace-Podcasts-as-New-Learning-T ools_29904.aspx

[18] Brown S. Seeing Web 2.0 in context: A study of academic perceptions. Internet and Higher Education. 2012 ; 15 : 50-57. http://dx.doi.org/10.1016/j.iheduc.2011.04.003

[19] Farr T. Using a blog to improve communication. Nursing Management. 2011; 42(6): 52-53. PMid:21629035 http://dx.doi.org/10.1097/01.NUMA.0000397925.11467.9b

[20] Fisher MA, Haley HL, Saarinen CL, Chretien KC. Comparison of blogged and written reflections in two medicine clerkships. Medical Education. 2011; 45(2): 166-175. PMid:21208262 http://dx.doi.org/10.1111/j.1365-2923.2010.03814.x

[21] Moule P, Ward R, Lockyer L. Nursing and healthcare students' experiences and use of e-learning in higher education. Journal of Advanced Nursing. 2010; 66(12): 2785-2795. PMid:20946565 http://dx.doi.org/10.1111/j.1365-2648.2010.05453.x

[22] Ironside PA. Trying something new: implementing and evaluating narrative pedagogy using a multimethod approach. Nursing Education Perspectives. 2003; 24(3): 122-128. PMid:12830682

[23] Tanner C. Spock would have been a terrible nurse and other issues related to critical thinking. Journal of Nursing Education. 1997; 32: 99-101.

[24] Scheffer BK, Rubenfeld MG. A consensus statement on critical thinking in nursing. Journal of Nursing Education. 2000; 39(8): 352-359. PMid:11103973

[25] Black G. Using supplemental journal articles to increase student participation, discussion and critical thinking. Journal of Business Administration Online. 2004; 3(2): 1-7.

[26] Duron R, Limbach B, Waugh W. Critical thinking framework for any discipline. International Journal of Teaching and Learning in Higher Education. 2006; 17(2): 160-166.

[27] Placing K, Ward MH, Peat M, Teixeira PT. Blogging in science and science education. Proceedings of the Blended Learning in Science Teaching \& Learning Poster Presentation. 2005. Available from:

http://openjournals.library.usyd.edu.au/index.php/IISME/article/view/6474/7121

[28] Galer-Unti R. Advocating 2.0: Advocating in the digital age. Policy and Politics. 2010; 11(6): 784-787. 
[29] Mulcahy M, Pierce ME. Critical Thinking, Collaboration, and Communication: The Three “Cs” of Quality Preoperative Screening. Journal of PeriAnesthesia Nursing. 2011; 26(6): 388-394. PMid:22099131 http://dx.doi.org/10.1016/j.jopan.2011.06.004

[30] Gesler WM. The cultural geography of health care. 1991. Pittsburgh, PA: University of Pittsburgh Press.

[31] Gesler WM, Kears RA. Culture/Place/Health. 2002. London:Routledge PMid:11933009

[32] Gastaldo D, Andrews G, Khanlou N. Therapeutic Landscape of the mind: Theorizing some intersections between health geography, health promotion and immigration studies. Critical Public Health. 2004; 14(2): 157-176. http://dx.doi.org/10.1080/09581590410001725409

[33] Ogden J. How meaningful are data from likert scale: An evaluation of how rating are made and the role of the response shift in the socially disadvantage. Journal of Health Psychology. 2011: 1-2. Available from:

http://www.academia.edu/895133/How_meaningful_are_data_from_Likert_scales_an_evaluation_of_how_ratings_are_made_an d_the_role_of_the_response_shift_in_the_socially_disadvantaged

[34] Miles M, Huberman A. Qualitative data analysis : An expanded source book (2nd ed.). 1994. Thousand Oakes: Sage.

[35] Sharma P. Enhancing student reflection using Weblogs: lessons learned from two implementation studies. Reflective Practice. 2010; 11(2): 127-141. http://dx.doi.org/10.1080/14623941003683201

[36] Thomas C. De-constructing concepts of care. Sociology. 1993; 27(4): 649-669. http://dx.doi.org/10.1177/0038038593027004006

[37] Bevis EO, Watson J. Toward a Caring curriculum: A New Pedagogy for Nursing. 1989. New York: National League for Nursing.

[38] Garno M. Transforming nursing through dialogical relationships: A pedagogy of connectedness. International Journal for Human Caring. 2010; 14(1): 21-26.

[39] Watson J. Caring theory as ethical guide to administrative and clinical practices. Nursing Administrative Quarterly. 2006; 30(1): 48-55. http://dx.doi.org/10.1097/00006216-200601000-00008

[40] Al Fadda H, Al Yahya M. Using web blogs as a tool to encourage pre-class reading, post-class reflections and collaboration in higher education. US-China Education Review. 2010; 7(7): 100-106.

[41] Williams J, Chinn S. Using web 2.0 to support the active learning experience. Journal of Information Systems Education. 2009; 20(2): 165-174. 